\title{
O PARADOXO DO ENSINO DA PERSPECTIVA DE UMA EPISTEMOLOGIA DO USO
}

\author{
Cristiane Maria Cornelia Gottschalk*
}

\begin{abstract}
RESUMO
Meu objetivo neste texto é apresentar o paradoxo do ensino e revisitar os modelos filosóficos de ensino examinados por Israel Scheffler, que procurou indicar as vantagens e dificuldades de cada um deles para, em seguida, propor um modelo filosófico de ensino que considerava mais satisfatório. No entanto, embora Scheffler tenha incorporado boa parte da crítica que a "virada linguística" faz à metafísica destes modelos, minha hipótese é a de que ao fazer a análise dos modelos de ensino empirista (Locke), idealista (Agostinho) e racional (Kant), ele não leva em consideração o papel distintivo das proposições gramaticais (no sentido de Wittgenstein) em relação às demais proposições, para compreender como é possível o crescimento do conhecimento no indivíduo. Da perspectiva de uma epistemologia do uso inspirada nas ideias do segundo Wittgenstein, argumento que, se considerarmos que estas proposições constituem nossa visão de mundo (Weltbild) e que aprendemos a seguir estas regras, a maior parte das dificuldades encontradas nestes modelos simplesmente desaparece, como também o paradoxo do ensino é dissolvido.
\end{abstract}

Palavras-chave: Modelos filosóficos de ensino. Wittgenstein. Significado. Epistemologia do uso.

\begin{abstract}
My goal in this paper is to present the 'teaching paradox' and to revisit the philosophical models of teaching examined by Israel Scheffler, who sought to point out the advantages and difficulties of each of them, to then propose a philosophical model of teaching that he considered more
\end{abstract}

\footnotetext{
* Doutora em Filosofia da Educação pela Universidade de São Paulo (USP). Professora no Departamento de Filosofia da Educação e Ciências da Educação da Faculdade de Educação da Universidade de São Paulo (USP) e coordenadora da área de Filosofia e Educação do Programa de Pós-graduação da Faculdade de Educação da Universidade de São Paulo (FEUSP). E-mail: crisgott@usp.br
} 
satisfactory. However, although he incorporated much of the criticism that the "linguistic turn" makes to the metaphysics of these models, my hypothesis is that, when doing the analysis of educational models empiricist (Locke), idealist (Augustine) and rational (Kant) -, he does not take into account the distinctive role of grammatical propositions (in the sense of Wittgenstein) regarding the other propositions, to understand how the growth of knowledge in the individual is possible. From the perspective of an epistemology of use inspired in the ideas of the second Wittgenstein, I argue that, if we consider that these propositions constitute our worldview (Weltbild) and that we learn to follow these rules, most of the difficulties encountered in these models simply disappear, and the paradox of teaching is also dissolved.

Keywords: Philosophical models of teaching. Wittgenstein. Meaning. Epistemology of use.

Diversas questões filosóficas, presentes desde os pré-socráticos, ressurgem no campo educacional com a mesma força que tinham entre os gregos, desafiando ainda hoje os filósofos da educação. Dentre elas, o paradoxo do conhecimento, explicitado por Platão em seus diálogos, na voz de Sócrates, ao criticar a doutrina erística dos sofistas, segundo a qual o homem não pode procurar o que sabe, nem o que não sabe, uma vez que "o que sabe, é claro, não precisa procurar, porque sabe; e o que não sabe, não pode procurar, porque não sabe o que deve procurar" (PLATÃO, 2001, 81). Este paradoxo foi retomado por Ryle, nos seguintes termos:

Considerem o caso de uma criança comum, que não é brilhante e nem estúpida, e que está aprendendo a ler. Ela aprendeu a soletrar e ler monossílabos, tais como, 'ver', 'lá', 'sem', 'tem' etc., e alguns dissílabos como 'sendo', 'visto' e alguns outros. Nunca ensinamos a ela, digamos, a palavra 'vendo'. No entanto, logo nos deparamos com ela lendo e soletrando sem hesitar a palavra 'vendo'. Perguntamos a ela quem lhe ensinou esta palavra e, se ela se recorda, dirá que descobriu sozinha. Aprendeu por si só como a palavra 'vendo' aparece impressa, como escrevê-la e como pronunciá-la em voz alta; assim, em certo sentido ensinou a si mesma esta palavra - ensinou-a a si mesma sem 
conhecê-la. Como isto pode ocorrer? Como pode uma criança que não sabe soletrar 'v-e-n-d-o' ensina a si mesma como soletrá-la? (RYLE, 1967, p. 106).

Ryle não está duvidando deste processo de aprendizagem, pois todos nós como professores esperamos que seja exatamente isto o que deva ocorrer. A partir de certo momento, a criança deve ser capaz de continuar por si só a ler palavras novas. A questão filosófica que permanece é análoga ao paradoxo do conhecimento. Como é possível uma criança aprender algo novo, que não fazia ainda parte de seu repertório, sem que tivesse sido ensinado por seu professor? Neste caso, o professor é tão ignorante quanto o aluno, uma vez que ambos se referem à mesma criança...

São diversas as respostas que são oferecidas a este paradoxo na história da filosofia da educação, amparadas em epistemologias idealistas, empiristas e pragmáticas. Cada uma delas apresentando um modelo considerado mais eficaz de ensino, tendo em vista a autonomia do aluno para 'seguir adiante', construindo novos conhecimentos. Dentre estes modelos, o filósofo da educação Israel Scheffler destacou três abordagens distintas que se propunham a pensar o ensino de qualquer matéria, analisadas por ele como o intuito de encontrar um modelo filosófico mais eficaz de ensino e aprendizagem, e que pudesse responder completamente à seguinte questão: quais são as condições que possibilitam o crescimento do conhecimento no indivíduo? Em outras palavras, o que permite ao aluno ser capaz de ir além de um determinado conhecimento ensinado pelo professor, aplicando-o em novas situações e adquirindo por si só novos conhecimentos?

Como veremos a seguir, as respostas dadas a esta questão, sugeridas a partir dos modelos de ensino abordados por Scheffler, recorrem, cada uma delas, a diferentes teorias epistemológicas. Procurarei mostrar que, todas elas desconsideram o papel da linguagem na constituição de sentidos, e que, se levarmos em conta algumas reflexões proporcionadas pela virada linguística do começo do século passado, não necessitaremos de nenhuma teoria fundamentando as práticas pedagógicas: basta olharmos como nosso aparato conceitual é efetivamente ensinado e aprendido, como nos sugere o filósofo Wittgenstein, em sua obra Investigações filosóficas (1996, \#66): "não pense, mas olhe!" 


\section{Três modelos filosóficos de ensino}

Começarei reproduzindo sucintamente os modelos de ensino apresentados por Scheffler, destacando as vantagens e dificuldades que ele encontra em cada um deles, para apresentar em seguida sua solução, obtida através da conciliação destas diferentes abordagens em um novo modelo, considerado por ele "mais satisfatório".

\section{1 modelo da impressão}

O primeiro modelo descrito é denominado por Scheffler de "Modelo da Impressão", derivado das ideias do empirista John Locke' ${ }^{1}$ :

Suponhamos então, que a mente seja, como dizemos, papel em branco, vazia de qualquer signo, sem nenhuma idéia; como ocorre de ser provida? (...) A isto respondo com uma palavra, da experiência, na qual todo nosso conhecimento está fundado, e da qual deriva em última instância. Nossa observação, empregada tanto em relação aos objetos sensíveis externos, como às operações internas de nossas mentes, percebidas e refletidas por nós próprios, é o que supre nosso entendimento com todos os materiais do pensamento. Estas duas são as fontes do conhecimento, das quais todas as idéias que temos, ou que podemos ter naturalmente, surgem (apud SCHEFFLER, 1967, p.121).

Como vemos a partir desta passagem, Locke vê o aprendiz como tabula rasa, que ao receber o input de ideias sensórias simples, armazena-as e passa a relacioná-las, generalizando seus conteúdos. Consequentemente, o papel do professor seria controlar esta entrada de unidades sensoriais, moldando, assim, a mente do aluno. Temos aqui uma concepção epistemológica empirista atomista, que tem como pressuposto básico a ideia de que o conhecimento deriva diretamente da experiência empírica ou mental, tendo como uma de suas implicações educacionais, a diretriz

\footnotetext{
1 As traduções do inglês para o português das passagens citadas dos artigos de Scheffler e de Ryle são de minha autoria.
} 
para que as experiências das crianças sejam as mais variadas possíveis e numerosas. No entanto, Scheffler destaca uma primeira dificuldade deste modelo:

As noções de idéias absolutamente simples e de poderes mentais abstratos que são desenvolvidos através de exercícios tem sido frequentemente e acertadamente criticados como mitológicos. Simplicidade é um conceito relativo, e não absoluto, que reflete um modo particular de análise da experiência; é, resumidamente, um conceito não dado, mas construído. E poderes mentais ou faculdades invariantes com o assunto da matéria, como todos sabem, têm sido descartados na psicologia como fundamentos tanto empíricos como teóricos (SCHEFFLER, 1967, p. 122).

A partir das considerações acima, Scheffler questiona a ideia de que o conhecimento seria alcançado através de um conjunto padrão de operações que processariam as partículas sensórias, lembrando-nos que o conhecimento envolve todo um aparato conceitual que não deriva de dados sensórios, mas pelo contrário, se impõe a eles. Ainda segundo ele, tampouco este aparato linguístico é construído na mente humana; ele seria, pelo menos em boa parte, um produto do trabalho de adivinhações e de invenção gerado na cultura e nos costumes (SCHEFFLER, 1967, p. 123). Lembra-nos, também, que a experiência é relevante para o conhecimento na medida em que propicia testes para as nossas teorias, onde estas são primordialmente fatos da nossa história e herança intelectual.

No entanto, poucas linhas depois, surpreendentemente, Scheffler apresenta o que chama de "variante verbal" do modelo de ensino da impressão, afirmando que esta variante teria afinidades com o behaviorismo contemporâneo, uma vez que neste modelo o "que deve ser impresso na mente não são apenas experiências sensórias, mas linguagem e, além de tudo, teorias aceitas" (SCHEFFLER, 1967, p. 123). Assim, esta variante do modelo de impressão teria apenas como pretensão o armazenamento de teorias aceitas sem a preocupação de ensinar o aprendiz a usá-las de modo apropriado nos diversos contextos. Ora, tem-se a impressão de que subitamente a linguagem parece perder sua importância, anteriormente 
destacada por ele como organizadora da experiência, pois agora afirma que sua função se reduz a um mero armazenamento de informações que não garantem a compreensão do que teria sido armazenado.

Por enquanto, aceitaremos o pressuposto implícito em sua crítica de que é possível ensinar proposições da linguagem sem que estas sejam de fato compreendidas, ou seja, que neste caso o aprendizado se reduz a um processo de memorização. O aluno até pode ser capaz de reproduzir informações, mas outra coisa seria tê-las compreendido efetivamente. Outro modelo, denominado por ele de "modelo do insight", supriria esta deficiência dos modelos da mera impressão (sensorial e/ou verbal) de não levarem em consideração o processo de compreensão do que é transmitido, condição para que haja de fato conhecimento.

\section{2 modelo do insight}

O modelo do insight remonta à concepção de visão interior de Agostinho, introduzida em seu diálogo $O$ mestre, onde o filósofo da patrística apresenta a tese de que novos conhecimentos não são transmitidos através das palavras, a menos que estas signifiquem realidades já presentes de algum modo na mente do aprendiz. Assim, é através de uma contemplação interior destas realidades que o aprendiz compreenderia as bases e possíveis aplicações do conhecimento transmitido. A linguagem apenas teria a função de evocar estas realidades já existentes a priori no aluno, que abrigaria em seu mundo interior uma centelha divina, pois todos fomos criados à imagem e semelhança de Deus. Em outras palavras, somos iluminados pelas verdades reveladas por Deus, o único que ensina verdadeiramente.

Esta concepção agostiniana de ensino e de aprendizado deu origem a um modelo filosófico de ensino, ainda bastante atual, onde a significação é vista como algo que independe da linguagem, e que se encontra na experiência interna ou externa. A linguagem apenas teria como função revestir estes significados, como se as palavras fossem meras "etiquetas" dos objetos a que se referem. A experiência destas realidades, portanto, seria anterior à linguagem e condição de compreensão dos enunciados transmitidos pelo professor. Segundo Scheffler, 
O modelo do insight é forte onde o modelo da impressão é fraco. Enquanto oúltimo, com sua preocupação em conservar o conhecimento, falha em fazer justiça à inovação, o primeiro remete-se desde o início ao problema do novo conhecimento resultante do ensino. Enquanto o último enfatiza as partículas atômicas e manipuláveis em detrimento do entendimento, o primeiro enfatiza primordialmente a aquisição de insight. Enquanto o último oferece um lugar desordenado para a alimentação dos materiais de fora, o primeiro enfatiza a importância da inspeção em primeira mão das realidades pelo estudante, a necessidade do estudante em obter seu conhecimento através de seus próprios esforços (SCHEFFLER, 1967, p. 125).

Embora Scheffler veja com simpatia a ênfase deste modelo no processo de compreensão, ainda não o considera satisfatório. Questiona a ideia de Agostinho de que não se transmite sentidos por meio da linguagem, uma vez que esta apenas incitaria o aluno a revolver os significados correlatos às palavras enunciadas ${ }^{2}$. As sentenças enunciadas transmitem sim sentidos, independentemente se cada uma de suas palavras remete a uma realidade interna ou externa ao aluno. A questão que permanece, então, é que embora seja possível a transmissão com sentido de novas informações, acreditadas pelos alunos, o mesmo não ocorre com novos conhecimentos. $\mathrm{O}$ conhecimento de proposições nas ciências, na política, história ou em qualquer outra área considerada, pressupõe o domínio de outros processos, tais como, saber deliberar, argumentar, julgar, apreciar as razões pró e contra, ou seja, capacidades que transcendem uma simples visão ou insight de uma realidade:

Saber a proposição expressa por uma sentença é mais do que apenas ter sido informado, ter apreendido seu significado, e tê-lo aceito. É ter obtido o direito, através de seu próprio esforço ou posição, para assegurar a sua verdade (SCHEFFLER, 1967, p. 127)

Em outras palavras, o modelo agostiniano não levaria em consideração o papel do conceito de princípios e do conceito associado de razões, bases para as noções de deliberação racional e julgamento

2 Os significados para Agostinho estariam nas próprias realidades acessadas pelo aprendiz após um processo de contemplação interior. 
crítico, como também para as noções de conduta racional e moral. Um modelo mais satisfatório deveria contemplar estes processos, o que conduz Scheffler ao modelo das regras, inspirado nas ideias de Kant.

\section{$1.3 \mathrm{O}$ modelo das regras}

Segundo Sheffler, Kant enfatiza a razão, e esta é fiel a regras e princípios gerais, interessada na verdade dos fatos e na correção dos atos morais. Assim, o ensino não deve se reduzir a uma mera transferência de informações e nem de um desenvolvimento de insight, mas também deve possibilitar a interiorização de "princípios de julgamento e condutas, a construção de um caráter autônomo e racional, que fundamentam as empresas das ciências, da moralidade e da cultura" (SCHEFFLER, 1967, p. 131). O próprio Kant sustenta que os princípios racionais estariam imersos de alguma forma na estrutura da mente humana e, neste sentido, a educação se assentaria em uma fundação sólida. Assim, este modelo teria o mérito de ressaltar a autonomia do julgamento do aluno, seu direito de procurar razões que sustentem as afirmações em jogo.

Não obstante, o julgamento racional, segundo Scheffler, envolve muito mais do que apenas uma consistência formal, guiado apenas por princípios abstratos. Se olharmos para as nossas práticas concretas, veremos que são guiadas por regras muito diversas, que variam com o campo de conhecimento e o seu estado da arte, regras que não estão imersas em uma mente... A noção de tradição seria mais propícia para descrever estes diferentes processos do que a pressuposição de uma estrutura inata na mente humana. A racionalidade está atrelada a diferentes domínios do saber, imersa nas múltiplas tradições, as quais deveriam ser um importante foco para o ensino.

$$
* * *
$$

Diante destas considerações, Scheffler propõe um novo modelo de ensino que incorpora o que considera importante em cada um dos modelos anteriores, mas que, ao mesmo tempo, leva em consideração a nossa herança cultural, cujos princípios são históricos e sociais, fundamentais em nossas formas de vida, para além de eventuais princípios gerais imersos em estruturas inatas da mente do indivíduo: 
O modelo de impressão reflete (...) o crescimento acumulativo do conhecimento em seu sentido público. Nosso objetivo no ensino deveria certamente ser a preservação e a extensão deste crescimento. Mas não podemos fazer isto armazenando-o aos pedaços no interior do aprendiz. Só o preservaremos, como o modelo do insight enfatiza, se tivermos sucesso em transmitir a centelha de vida que o faz crescer, o insight que é produto dos esforços de cada aprendiz em dar sentido ao conhecimento público nos seus próprios termos, e ao confrontá-lo com a realidade. Finalmente, como o modelo das regras sugere, tal confrontação envolve deliberação e julgamento, e portanto pressupõe princípios gerais e imparciais governando a apreciação de razões que dão suporte às decisões. Sem tais princípios norteadores, a própria concepção de deliberação racional colapsaria, e mais ainda, perderia seu significado. Nosso ensino precisa assim introduzir os estudantes a estes princípios que nós próprios reconhecemos como fundamentais, gerais, e imparciais, nos vários departamentos do pensamento e da ação (SCHEFFLER, 1967, p.133).

Scheffler conclui dizendo que o ensino, nesta sua última acepção, não teria um caráter behaviorista (no sentido do professor simplesmente moldar ou controlar a mente do aluno), mas sim uma atividade que transmite tradições fundamentadas em princípios que regem nosso pensamento e ações. Mas quais seriam, então, estes princípios mais fundamentais? Qual seria a natureza destas regras que reconhecemos como gerais e imparciais? Como são transmitidas e como operam? O que seria esta compreensão que possibilita o crescimento do conhecimento no aluno? Penso que estas são questões que merecem uma investigação mais aprofundada, não com a intenção de encontrar um modelo filosófico de ensino ainda mais satisfatório... mas com a expectativa de esclarecer algumas das dificuldades apontadas por Scheffler nos três modelos de ensino caracterizados por ele, e, a partir de algumas ideias do segundo Wittgenstein ${ }^{3}$, retomar a variante

\footnotetext{
Wittgenstein é considerado o maior representante da "virada linguística", movimento do final do século XIX e início do século XX. Este movimento passa a considerar o papel da linguagem na constituição dos significados, propondo-se uma ideografia que desse conta do pensamento e que eliminasse a imprecisão da linguagem ordinária. Consideraremos nesta comunicação as idéias do segundo Wittgenstein, que abandona o projeto de uma
} 
verbal do modelo filosófico da impressão, tão apressadamente descartada por Scheffler por considerá-la alinhada ao behaviorismo contemporâneo.

\section{Seguir regras e a "virada linguística"}

Segundo o filósofo austríaco Wittgenstein, toda atividade linguística é guiada por regras, mas isto não significa que somos determinados por elas. Empregamos palavras e expressões da nossa linguagem com diferentes sentidos, dependendo do contexto linguístico ou pragmático em que ocorrem. Uma sentença, por exemplo, não se reduz a um amontoado de palavras, pois está envolvida com atividades que são constitutivas da significação. Daí Wittgenstein utilizar o termo “jogo de linguagem”, para enfatizar o papel destas atividades que operam como regras constitutivas do sentido de nossos enunciados. Quando enuncio a frase, "todo objeto é idêntico a si mesmo", esta é uma regra linguística que orienta o meu pensamento quando descrevo objetos como mesas, cadeiras, ou qualquer outro objeto empírico. Não tem sentido dizer, por exemplo, que esta é uma cadeira $e$ um elefante: este objeto ou é uma cadeira, ou é um elefante...

Mas os próprios objetos empíricos também podem desempenhar o papel de regras! Se alguém ainda não sabe o que é um elefante, posso leválo a um zoológico, apontar para um elefante e dizer: "Isto é um elefante!". O animal apontado passa então a ser um paradigma do que é ser um elefante, uma amostra de elefante que a linguagem incorpora para ir constituindo o significado da palavra "elefante". Neste sentido, o objeto elefante passa a ser uma regra do que é ser elefante. O próprio gesto ostensivo que aponta para o elefante também pode ser considerado uma regra, na medida em que faz a ligação entre o som da palavra "elefante" e a amostra de um elefante. Este gesto faz parte do jogo de linguagem da nomeação, é uma regra que permite atribuirmos sentido à palavra elefante. E, assim, vamos aprendendo a seguir regras que são internalizadas pouco a pouco, constituindo o que Witttgenstein vai denominar de uma gramática que carregamos dentro

ideografia e propõe que não formulemos teorias, mas que olhemos como de fato usamos nossas expressões linguísticas. 
de nós, constituída por afirmações que não questionamos, e que guiam o nosso pensamento e nossa ação ${ }^{4}$.

Assim, pensamos e agimos seguindo regras, expressas não só por enunciados como "todo objeto é idêntico a si próprio" ou "isto é um elefante" (apontando-se para um elefante empírico ou para a imagem de um elefante), como também através de enunciados como "meu nome é X", "a palavra elefante tem oito letras", "eu existo" etc., convicções que trazemos dentro de nós e que não questionamos em hipótese alguma (MORENO, 1995 , p. 75). São certezas que não têm um valor de verdade, pois não são consideradas por nós verdadeiras ou falsas. Segundo Wittgenstein, são usadas como condições de sentido para as demais proposições da nossa linguagem, são as regras que seguimos para atribuir sentido às nossas ações e pensamentos.

Desta perspectiva wittgensteiniana, retornemos ao modelo da impressão. Concordamos com Scheffler quando este questiona o modelo empirista inspirado nas ideias de Locke, que afirma que todo o conhecimento deriva em última instância dos dados sensórios. De fato, se olharmos para as nossas práticas linguísticas, veremos que não é o empírico que irá determinar o significado de nossas palavras, mas é a própria linguagem que organiza os dados sensórios de determinadas maneiras. Mas e a variante verbal deste modelo? Se a linguagem tem o papel de organizar a experiência interna ou externa, por que teorias transmitidas pelo professor (através da linguagem) apenas controlariam o pensamento do aluno, cuja mente seria moldada por elas? Por que haveria uma mera transmissão de informações e não de conhecimento?

Segundo Scheffler, como vimos, não há conhecimento se não houver compreensão do que está sendo dito. Uma mera memorização não envolve o entendimento daquela informação, que estaria sendo apenas "armazenada" na mente do aluno. Entretanto, compreendê-la envolveria um processo de insight, exigido pelo modelo agostiniano de ensino: seria ter acesso às próprias realidades, sejam elas internas (na mente do aluno) ou externas (no mundo empírico). Revela-se, aqui, uma concepção referencial

4 A sistematização destas ideias de Wittgenstein foi feita por Arley Ramos Moreno em sua obra Introduction à une épistemologie de l'usage (2011). 
da linguagem: a informação apenas se torna um verdadeiro conhecimento quando temos acesso ao que ela se refere. Como se o significado de uma expressão linguística fosse o fato a que ela se refere, como se a linguagem tivesse apenas uma função descritiva.

Como já expusemos em outros momentos, Wittgenstein ressalta outros modos de utilização da linguagem, para além da descrição. Entre eles, o uso normativo da linguagem, em particular quando se trata de proposições que são usadas com convicção absoluta: tenho certeza que meu nome é X, que a palavra "elefante" tem oito letras, que existo, etc. Estas expressões não se referem a nada, não são, como vimos acima, nem verdadeiras nem falsas. Muitas vezes não são nem ao menos explicitadas, são aprendidas ao longo do uso de linguagem em meio a diversas atividades.

Assim, quando um professor ensina determinadas teorias que são aceitas em nossa cultura, o que significaria "armazená-las"? Segundo o próprio Wittgenstein, ao se ensinar através de livros escolares, nem todas as proposições são igualmente sujeitas à prova, não recorremos necessariamente a algum tipo de experiência como critério último de aceitação destas teorias:

Em geral consideramos como verdadeiro o que se encontra em livros escolares de geografia, por exemplo. Por quê? Eu digo: todos esses fatos foram confirmados centenas de vezes. Mas como eu sei disso? Qual é a evidência que tenho para isso? Eu tenho uma imagem do mundo [Weltbild]. É verdadeira ou falsa? Acima de tudo, é o substrato de toda minha investigação e asserções. As proposições que a descrevem não são todas igualmente sujeitas a prova (WITTGENSTEIN, 1998, \#162).

Nesta passagem, Wittgenstein chama nossa atenção para um tipo de proposição que não é obtida através de um processo de indução ou da observação empírica, trata-se de proposições que são como “engolidas” pelo aprendiz, e que na sua totalidade formam nossa imagem de mundo (Weltbild). Assim, não são princípios gerais no sentido kantiano de uma racionalidade inata e tampouco se referem a experiências prévias do aprendiz. Têm a função de regras, que seguimos cegamente (WITTGENSTEIN, 1998, 
\#219), e são elas as condições para compreendermos outras proposições, estas sim, eventualmente descritivas de realidades empíricas. Compreender, portanto, tem um certo parentesco com "ser capaz de seguir uma regra", ser capaz de agir orientado por ela:

Seguir uma regra é análogo a cumprir uma ordem. Treina-se para isto e reage-se à ordem de uma maneira determinada. Mas como entender isso se a reação das pessoas tanto diante da ordem como diante do treinamento é diferente: um reage assim e o outro de modo diferente? Quem está então com a razão?

Imagine que você fosse como pesquisador a um país desconhecido cuja língua você desconhece completamente. Em que circunstâncias você diria que as pessoas de lá dão ordens, entendem as ordens, cumprem ordens ou se insurgem contra elas etc.?

O modo de agir comum dos homens é o sistema de referência por meio do qual interpretamos uma língua estrangeira (WITTGENSTEIN, 1998, \#206).

Como vemos nesta passagem, entender uma regra, do mesmo modo que seguir uma regra, pressupõe um modo comum de agir: temos critérios públicos para avaliar se a regra foi seguida ou transgredida. Quando um professor de geometria ensina que "triângulo é um polígono fechado de três lados”, esta é uma regra que seguimos na matemática para aplicar o conceito de triângulo. Esta regra não descreve uma entidade ideal em um reino transcendente, apenas define o que é ser triângulo neste campo do conhecimento. É uma regra para o uso da palavra. Compreender o que é triângulo é saber seguir esta ou alguma outra regra de utilização da palavra "triângulo".

Neste sentido, o conhecimento que vai sendo "armazenado" pelo aluno não é homogêneo. Parte deste saber tem uma função descritiva, suas proposições dizem como as coisas são, enquanto que outra parte deste saber tem uma função constitutiva dos significados que atribuímos às nossas experiências em geral, dizem $o$ quê as coisas são. E é este saber com função normativa, transmitido pelo professor ou através dos livros, que será a condição de crescimento do conhecimento no indivíduo. É nesta porção do conhecimento transmitida pelo professor que diversos elementos 
atuam como regras na constituição dos significados: palavras envolvidas com gestos, ações, objetos empíricos, sensações etc. Compreender algo, portanto, pressupõe o domínio destas regras, o que envolve um certo treino, pois estas regras são aprendidas, não são extraídas do empírico e tampouco são inatas. São de natureza convencional. Fazem parte de uma forma de vida.

A dificuldade, portanto, nos modelos filosóficos de ensino descritos acima, é a de ignorar as diferentes funções desempenhadas pela nossa linguagem. Formulamos teorias para tentar explicar o abismo entre os princípios mais fundamentais e como operamos com eles, e nos esquecemos de olhar para o uso efetivo de nossas expressões linguísticas: ora como normas, ora como proposições empíricas.

Enfim, nem todo conhecimento refere-se a algo, e tampouco compreender uma informação equivale a ter acesso às supostas evidências experimentais sobre as quais se apóia. Há um tipo de saber que não se refere a nada, e que é constituído pelo que Wittgenstein denomina de proposições gramaticais. Estas não são passíveis de serem conhecidas, são apenas condições de sentido de outras proposições: têm o caráter de regras. Somos treinados a segui-las. Novamente uma proximidade com o behaviorismo, que havia sido repelido por Scheffler?

\section{Formas de vida}

Embora as proposições gramaticais sejam de natureza convencional (não são reflexos de uma estrutura inata ou decorrentes da experiência) na medida em que estão ancoradas em nossas formas de vida, elas não determinam nosso pensamento e nossas ações. É no ensino destas regras e pelos exemplos de sua aplicação que vamos sendo treinados a segui-las, orientados por elas. Elas não nos dizem $o$ que fazer, apenas regulam a nossa ação. Daí a metáfora utilizada por Wittgenstein, "jogo de linguagem". Como em um jogo qualquer em que o aprendizado das regras não prevê o curso das jogadas, também o uso das palavras não é limitado rigidamente pelo seguimento de regras (IF \#68).

Temos critérios públicos que nos dizem se estamos agindo de acordo com a regra, ou se ela está sendo transgredida. Como afirma 
Wittgenstein na passagem acima, é o modo de agir comum que fornece o sistema de referência para a sua interpretação. Mesmo que um aluno procurasse razões últimas para estabelecer a verdade de uma afirmação, as razões têm um fim, há um momento em que esbarramos na "rocha dura" como diz Wittgenstein: "Se esgotei as justificativas, cheguei então à rocha dura, e minha pá se entorta. Estou inclinado a dizer então: 'É assim mesmo que ajo"" (WITTGENSTEIN, 1996, \#217). Assim, antes mesmo de sermos capazes de expor razões que assegurem a verdade de uma proposição, aprendemos a agir de determinadas formas que vão compondo a nossa visão de mundo. Estas ações são envolvidas com as palavras da nossa linguagem e passam a compor as condições de sentido de nossas afirmações sobre o mundo, que poderiam ser outras, em outras formas de vida.

Assim, cairíamos em algum tipo de behaviorismo se considerássemos a linguagem como tendo um único uso: o referencial. Mas ao levarmos em conta a existência de proposições gramaticais, a maior parte das dificuldades encontradas por Scheffler nos diferentes modelos abordados simplesmente desaparecem... Estas proposições de natureza convencional não justificam nossos conhecimentos em um sentido causal (Locke), não são reflexo de alguma realidade interna ou externa (Agostinho) e tampouco fazem parte de uma estrutura inata (Kant). Também não se reduzem aos princípios gerais e imparciais encontrados nas mais diferentes tradições de nossa herança cultural (Scheffler). Simplesmente são condições de sentido para outras proposições. Compreendê-las é saber segui-las em situações novas, mesmo inusitadas e, eventualmente, ser capaz de inventar novas regras, ou seja, imaginar novas condições de sentido.

Deste modo, o paradoxo do ensino formulado por Ryle é dissolvido. Uma criança quando aprende a ler aprende concomitantemente a seguir regras de natureza convencional, regras que não se reduzem a um saber meramente proposicional, pois pressupõem um modo de agir: somos treinados a soletrar as palavras de um determinado modo, a saber, da esquerda para a direita, lemos de cima para baixo, enfim, processos de memorização são acompanhados de ações enraizadas em nossas formas de vida, e que se tornam as condições de construção do conhecimento significativo, permitindo que "sigamos em frente". Podemos, então, responder tanto aos sofistas como aos platônicos: o conhecimento é sim 
possível, mas seus fundamentos devem ser aprendidos, o que pressupõe o treinamento em diversas técnicas de natureza convencional.

\section{Referências}

AGOSTINHO. O mestre. São Paulo: Landy Editora, 2002.

MORENO, Arley Ramos. Wittgenstein - através das imagens. Campinas: Unicamp, 1995. . Introduction à une épistemologie de l'usage. Paris: L'Harmattan, 2011.

PLATÃO. Mênon. Rio de Janeiro: PUC-Rio; Loyola, 2001.

RYLE, Gilbert. Teaching and training. In: PETERS, R. S. (Org.). The concept of education. Londres: Routledge \& Keagan Paul, 1967. p. 105119.

SCHEFFLER, Israel. Philosophical models of teaching. In: PETERS, R. S. (Org.). The concept of education. Londres: Routledge \& Keagan Paul, 1967, p. 120-134.

WITTGENSTEIN, Ludwig. Investigações filosóficas. Petrópolis: Vozes, 1996.

. On certainty. Oxford: Blackwell Publishers Ltd, 1998.

Data de registro:10/04/2012

Data de aceite:03/10/2012 